\title{
Title: The challenge of Antimicrobial Resistance: What economics can contribute
}

Authors: Laurence S. J. Roope ${ }^{1,2,3}$, Richard D. Smith ${ }^{4 *}$, Koen B. Pouwels ${ }^{5,6}$, James

$5 \quad$ Buchanan $^{1,2}$, Lucy Abel ${ }^{3,7}$, Peter Eibich ${ }^{8}$, Christopher C. Butler ${ }^{2,7}$, Pui San Tan ${ }^{7,9}$, A. Sarah Walker $^{2,3,10}$, Julie V. Robotham ${ }^{2,5}$ and Sarah Wordsworth ${ }^{1,2,3}$

\section{Affiliations:}

${ }^{1}$ Health Economics Research Centre, Nuffield Department of Population Health, University of Oxford, United Kingdom.

${ }^{2}$ The National Institute for Health Research Health Protection Research Unit in Healthcare Associated Infections and Antimicrobial Resistance at the University of Oxford, United Kingdom.

${ }^{3}$ NIHR Oxford Biomedical Research Centre, John Radcliffe Hospital, University of Oxford, United Kingdom.

${ }^{4}$ University of Exeter Medical School, St Luke's Campus, Exeter, EX1 2LU.

205 Modelling and Economics Unit, National Infection Service, Public Health England, UK.

${ }^{6}$ Department of Health Sciences, Global Health, University Medical Centre Groningen, University of Groningen, Groningen, The Netherlands. 
${ }^{7}$ Nuffield Department of Primary Care Health Sciences, University of Oxford, United Kingdom.

${ }^{8}$ Max Planck Institute for Demographic Research, Konrad-Zuse-Straße 1, 18057 Rostock, 5 Germany.

${ }^{9}$ Department of Medical Epidemiology and Biostatistics, Karolinska Institutet, Sweden.

${ }^{10}$ Nuffield Department of Clinical Medicine, University of Oxford, John Radcliffe Hospital, 10 University of Oxford, United Kingdom.

*Correspondence to: rich.smith@exeter.ac.uk 


\begin{abstract}
As antibiotic consumption increases, bacteria are becoming increasingly resistant to treatment. Antibiotic resistance undermines much of modern healthcare, which relies on access to effective antibiotics to prevent and treat infections associated with routine medical procedures. The resulting challenges have much in common with those posed by climate 5 change, which economists have responded to with significant research that has informed and shaped public policy. Drawing on economic concepts such as 'externalities' and the 'principal-agent relationship', we suggest how economics can help to solve the challenges arising from increasing resistance to antibiotics. We discuss solutions to the key economic issues; from incentivizing the development of effective new antibiotics, to improving 10 antibiotic stewardship through financial mechanisms and regulation.
\end{abstract}

One Sentence Summary: Climate change economics could help to guide policy for managing antibiotic resistance by reducing use and incentivizing new drug development. 


\section{Main Text:}

Before the discovery of penicillin by Alexander Fleming in 1928, and its subsequent development as a medicine by Howard Florey and Ernst Chain, death from infection could follow from something as minor as a simple scratch. Today, in high-income countries people

5 take for granted the relative safety of procedures such as caesarean sections, joint replacements and chemotherapy - all of which would be much more dangerous, perhaps prohibitively so, without effective antibiotics (1-3).

These gains in healthcare are now under threat from antimicrobial resistance (AMR). Here, we exclusively consider resistance against antibiotics used to treat bacterial infections.

10 Resistance is driven heavily by the ubiquitous use of antibiotics, often with little or no therapeutic benefit. For instance, antibiotics are commonly used for viral respiratory ailments (4), and used non-therapeutically in agriculture for livestock growth promotion (5). Additionally, widespread use of broad-spectrum antibiotics, which are effective against a broad range of bacteria, has greater potential for selecting for extensive antibiotic resistance than drugs that target specific bacteria. However, it is important to acknowledge that even socalled 'appropriate' use contributes to the development of AMR.

The potential costs to human life and to the economy are sobering. Recent UK government-commissioned reports $(6,7)$ estimate that without action by 2050 AMR will cause up to ten million annual deaths globally, reduce gross domestic product (GDP) by $2-$

$203.5 \%$, and cost US\$100 trillion. The World Bank (8) has estimated that the impact on global GDP may be even greater, with an annual cost of up to US\$ 3.4 trillion by 2030 . Current estimates such as these are necessarily based on limited data and contestable assumptions, and some have questioned their utility (9). Notwithstanding their limitations, these projections exceed the current burden due to cancer, both in terms of mortality and cost (10).

25 They also place the costs of AMR on a par with the best current estimates of the loss in GDP 
associated with a $2{ }^{\circ} \mathrm{C}$ rise above pre-industrial levels in global average surface temperature (just under 3\%) (11). In September 2016 AMR became only the fourth health issue, after HIV, non-communicable diseases and Ebola, to be discussed at the United Nations General Assembly. Analogous to the United Nations' 2015 Paris Agreement to limit global

5 temperature to $1.5^{\circ} \mathrm{C}$, pressure is mounting for a similar international commitment to tackle $\operatorname{AMR}(12)$.

Within economics, there has been some discussion of how AMR may be conceptualized and the difficulties of incorporating the large and uncertain future costs of AMR into assessments of health technologies $(13,14)$. Beyond this, however, discussion of

10 AMR within economics has been limited. At the time of writing, of more than one million peer-reviewed articles in Econlit only 55 relate broadly to AMR. By contrast, 16,306 articles relate to climate change. We discuss what might be learned from this extensive economic literature on climate change to inform both current policy and future economic research on AMR. A key feature of both global challenges is that there are adverse future consequences

15 from consuming antibiotics and carbon today, but substantial uncertainty over the timing and extent of these consequences. AMR also poses unique challenges that do not have an equivalent in climate change. Here, we examine some of the concepts underlying these challenges and highlight prospects for future research on the economics of AMR.

\section{The scientific background}

When Fleming, Chain and Florey were awarded the Nobel Prize in 1945, they sounded an early warning that, due to natural selection, bacteria could become resistant to antibiotics. They worried that sub-therapeutic antibiotic doses would 'educate' bacteria to resist antibiotics. While this still may hold (15), most concerns are currently about common commensal bacteria being unnecessarily exposed to antibiotics in the treatment of bacterial 
(or even viral) infections. The more these commensal bacteria are exposed to antibiotics, the greater the risk of antibiotic resistance in subsequent infections. Nevertheless, the warning of future antibiotic ineffectiveness was prophetic and AMR is now associated with substantial morbidity and costs (16), which will continue to rise if resistance increases. Estimating the

5 potential economically justified levels of investment in the development of new antibiotics and interventions that reduce unnecessary antibiotic use requires predictions of future levels of antibiotic resistance at the population level. However, modelling the trajectory of antibiotic resistance is complex (17).

\section{$10 \quad$ Uncertain future extent of AMR}

The use of an antibiotic may not only select for resistance against itself, but may co-select for resistance against other antibiotics (18), or even result in susceptibility to other antibiotics (19). Thus, without detailed understanding of the underlying mechanisms and interactions it is difficult to estimate the overall effect of changes in antibiotic consumption on resistance

15 levels. Although the emergence of mutations conferring resistance to certain antibiotics is predictable, the spread of new resistance genes into widespread bacterial strains are so-called Black Swan events (17). Such events will happen, but their timing, magnitude and impact are difficult to predict $(17,20)$.

\section{Reversibility of AMR and renewability of antibiotics}

While increased selection pressure from rising antibiotic use makes greater resistance inevitable, it is not clear that decreasing antibiotic use will necessarily be followed by a reduction in resistance (21). Most antibiotic resistance mechanisms are associated with a fitness cost, which reduces competitiveness in the absence of a drug and may allow susceptible bacteria to regrow. However, compensatory evolution, which reduces the fitness 
disadvantage of the resistance mechanism is widespread among bacteria, and limits the effectiveness of reducing antibiotic use (21-23). Whether fitness costs or genetic compensation prevail in natural infections is poorly understood (24).

Another important parameter determining the potential impact of changing antibiotic

5 prescribing is co-selection of resistance to more than one antibiotic (21). Some empirical evidence suggests that the effect of reducing use of an antibiotic depends on what, if any, antibiotic it is replaced by. In an effort to reduce resistance in pathogenic strains of Escherichia coli, use of trimethoprim and sulfonamide antibiotics was reduced in the UK and Sweden. Disappointingly, this particular policy was not followed by substantial reductions in

10 antibiotic resistance $(25,26)$. However, the lack of effect was largely explained by the replacement of trimethoprim and sulfonamide with antibiotics that shared genetically linked resistance mechanisms and were therefore subject to co-selection $(18,25,26)$, resulting in AMR being maintained in the population.

This work emphasizes the importance of understanding the precise mechanisms of

15 resistance for each antibiotic before rolling out policies to reduce use of one in tandem with increased use of another $(18,27)$. It can be beneficial to have several different antibiotics to treat a given infection, which disable bacteria in different ways. In this respect antibiotics contrast with most other drugs, where there is generally little to no clinical benefit associated with producing a new drug that is only equally as effective as an existing one. A new

20 antibiotic that matches the effectiveness of existing antibiotics, but disables bacteria in a different way, is valuable if it will remain effective in the future once existing antibiotics become clinically useless. In this way, having access to a diverse set of antibiotics reduces the likelihood that infections become untreatable as a result of universal resistance (17). 
As resistance to antibiotics accelerates, so too does the urgency of developing effective new antibiotics. Developing any new drug is expensive, risky and highly likely to be unsuccessful. Unfortunately, the pace of development of antibiotics is slow, in part because of the challenging logistics and high costs of large clinical trials $(28,29)$. Even if successful, the need to conserve effective new antibiotics means that they will have restricted use, and their clinical utility will decline as resistance to them inevitably develops. All these factors will limit the volume of antibiotic sales, and therefore the profits pharmaceutical companies reap from their development. Without government intervention, the high cost of drug development and poor sales prospects mean that, on average, antibiotic research and development projects make a substantial loss, and few companies continue to pursue them (30). In July 2018 Novartis joined a growing list of major pharmaceutical companies who have abandoned antibiotic development owing to lack of financial incentives.

It is now widely recognized that better incentives are needed to encourage pharmaceutical companies to re-engage with antibiotic development. Incentivization will require 'push' incentives, such as research grants and tax credits, to bring down R\&D costs. In addition, a variety of 'pull' mechanisms aimed at providing sufficiently attractive returns on investment for developers have been proposed. A critical aspect is that the development of new antibiotics needs to be profitable regardless of prices and sales volumes, as the existing model provides little incentive to produce a product that must be conserved (31-34).

\section{Impact of AMR on health and the economy}

Current worldwide deaths attributable to AMR, including antimalarial and antiviral resistance, have been estimated at around 700,000 per annum, rising to 10 million per annum by 2050 if present trends continue (Fig. 1). Antibiotic resistance levels vary across the world (35). These estimates have many limitations that need to be addressed in future work to gain 
a more accurate picture of the extent of global AMR. For example, estimates are sensitive to frequency of blood culture sampling. In resource poor settings where cultures are often only obtained from patients that do not respond to empirical treatment, resistance estimates will be inflated (9).

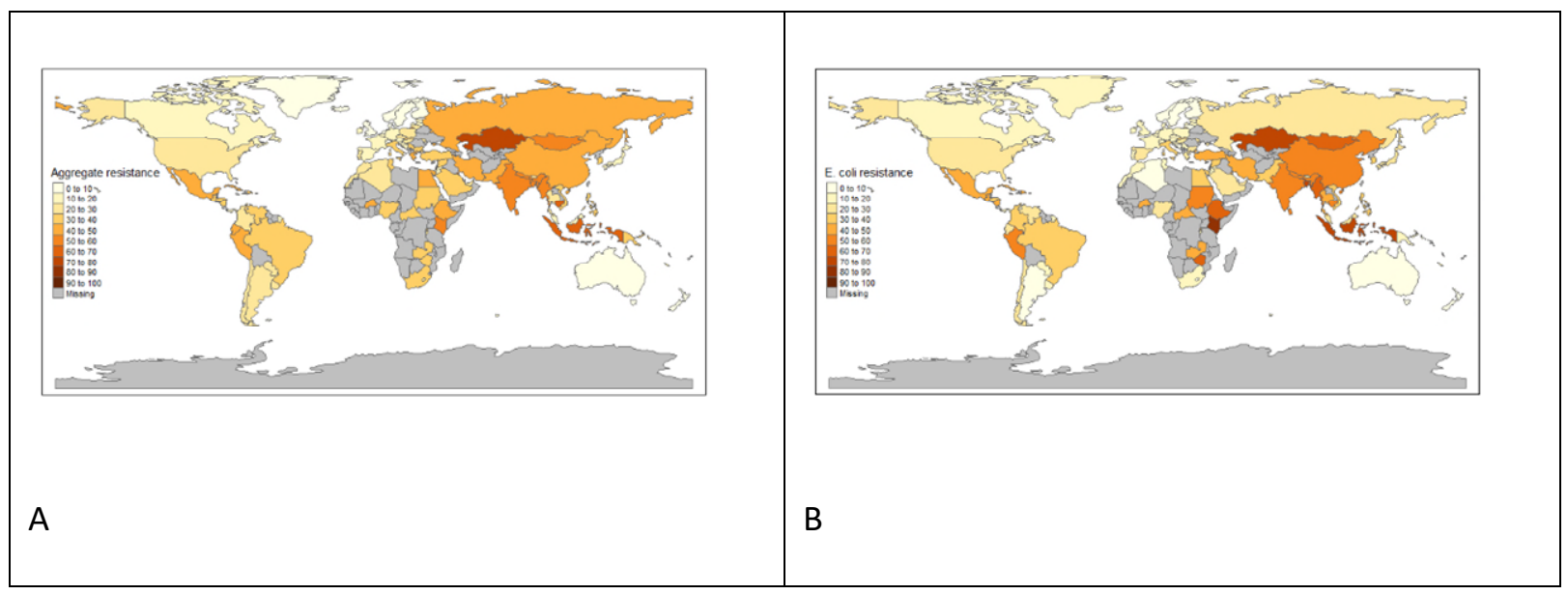

Fig. 1 Global antibiotic resistance levels (A) Global aggregate resistance. Aggregate resistance is defined as the average resistance prevalence of E. coli, Klebsiella spp., and Staphylococcus aureus; includes data on E. coli and Klebsiella spp. resistance to third-generation cephalosporins, fluoroquinolones, and carbapenems, and methicillin-resistant Staphylococcus aureus. [Data are from (35)]

(B) Global E. coli resistance is defined as the average prevalence of resistance of E. coli to third-generation cephalosporins and fluoroquinolones. [Data are from (35)]

\section{Direct and indirect consequences}

15 AMR can result in treatment failures as well as normally uncomplicated infections becoming more complicated and severe (36). Increasing complication leads to increased risk of chronic conditions and death, longer hospital stays, even greater risks for patients with frequent infections, such as cystic fibrosis, and a need for more toxic antibiotics if others fail owing to resistance. A review of papers that have tried to estimate the costs of AMR (2) per patient episode showed additional costs varied from less than $\$ 5$ to more than $\$ 55,000$. Yet these papers only estimated the direct healthcare costs, such as additional hospitalizations. 
However, in a world where antibiotic prophylaxis is no longer effective, there will be severe indirect consequences and costs, from additional infections following invasive surgical procedures and immunosuppressive chemotherapy (3). It has recently been estimated that a $30 \%$ reduction in the efficacy of antibiotic prophylaxis for surgical procedures and

5 chemotherapy would result in 120,000 additional infections and 6,300 infection-related deaths per year in the USA (3).

\section{Wider economic impact of AMR beyond healthcare}

In a recent review of estimates of the burden of AMR, only 11 of 214 studies estimated the

10 wider economic burden beyond the healthcare sector and only two did so at a global level (16). Measuring the economic impact of AMR solely on healthcare misses broader social costs and benefits of interventions to stem AMR (37). The loss of effective antibiotics may have a substantial effect on the health and productivity of the wider workforce (38-40). It has been estimated that caesarean sections, joint surgery, chemotherapy and organ transplants contribute almost $4 \%$ to global GDP (6). This gives a rough indication of the scale of economic impact if AMR rendered these procedures so dangerous that they were abandoned. Estimates of the total cost of AMR are fraught with uncertainty and there is a risk of the cost being far higher than current best estimates. Much of the uncertainty arises from the complexity of estimating the cost of changes in overall resistance levels. For example, if there is a $1 \%$ increase in resistance to drug $\mathrm{X}$, then it matters what pathogen is exhibiting that resistance, what the prevalence of that pathogen is, what type of infection it causes, the health burden of those infections, how transmissible it is - both between people and between organisms - and whether there are alternative treatments available. Since the cost of increased resistance, and the threat that it poses are uncertain, the investment that can be justified to control the threat, and ultimately the value of antibiotics, are also uncertain. 


\section{Incentivising socially desirable antibiotic consumption}

To reduce antibiotic consumption to socially desirable levels, we must first consider the reasons why many people take antibiotics unnecessarily. One major factor is imperfect

5 information, as antibiotics are often not essential, or even beneficial. Secondly, how are people and organizations incentivized to prescribe, consume and produce antibiotics? We must also not lose sight of the fact that many people in low- and middle-income countries (LMICs) still struggle to access life-saving antibiotics. Economics has a number of concepts that can help understand antibiotic consumption.

\section{The principal-agent problem, asymmetric information and moral hazard}

In healthcare a doctor usually acts on behalf of the patient, who benefits from the doctor's greater knowledge and skill. In economics, this scenario is known as the principal-agent relationship and applies to situations when a person or institution (the 'agent') makes

15 decisions or takes actions on behalf of (or that impact) another person or institution (the 'principal').

However, principal-agent relationships can give rise to a 'moral hazard' - if the agent's own best interests do not align, or even conflict, with those of the principal. The principal-agent relationship between doctors and patients and, more broadly, between doctors

20 and society, can be problematic $(41,42)$. Patients are less likely than doctors to know if antibiotics are inappropriate, such as when a condition is caused not by a bacterium but by a virus, or is a self-limiting illness. Patients are also less likely to realize that antibiotic use causes adverse consequences, for themselves and society, through increased resistance i.e., a negative 'externality' (43). When prescribing and dispensing are not separated, doctors can have financial incentives to prescribe. For example, in both China and Switzerland, countries 
with otherwise contrasting healthcare and social contexts, a lack of separation of prescribing and dispensing increases antibiotic prescribing $(44,45)$. Even without financial incentives, physicians are more likely to prescribe antibiotics if they think that their patients want them (46). Even if doctor and patient preferences for antibiotic use align, they may not reflect the 5 best interests of society more broadly (43).

The imbalance in the doctor-patient relationship could be relieved by altering incentive structures and through better education and public information campaigns for patients $(47,48)$. Alternatively, building upon the system proposed to contain carbon emissions, a tradable permit system could be organized in which doctors or their institution

10 are incentivized to reduce antibiotic prescriptions within a regulated optimum level (49).

Imperfect information on the part of physicians is another significant source of unnecessary antibiotic use. Without reliable rapid diagnostic tests, physicians can sometimes only make educated guesses as to whether infections need antibiotics and, if so, whether they will be susceptible to first-line antibiotic treatment. As with antibiotic development, a combination of push and pull incentives could incentivize the development of novel diagnostic tests (31). As well as reducing use of antibiotics for viral or self-limiting bacterial infections, better diagnostic tests could improve the feasibility of R\&D for innovative narrow-spectrum antibiotics. Empirical clinical use of such antibiotics could even become feasible for life-threatening infections if suitable rapid diagnostic tests were available (31, $50)$.

\section{Access versus excess}

Brazil, Russia, India, China and South Africa accounted for three-quarters of the increase in antibiotic consumption during 2000-2010 (51). Although there is substantial variation in consumption even among countries in similar income groups, the overall consumption pattern 
has shifted towards broader-spectrum antibiotics $(51,52)$. Yet lack of, and delays in, access to any antibiotics still results in more deaths worldwide than antibiotic resistance (53). Over one million children with untreated pneumonia and sepsis die annually (54). Across a sample of 101 countries (almost exclusively LMICs), it is estimated that universal provision of

5 antibiotics could avert $75 \%$ of 590,000 annual deaths from pneumonia in children under five (51). However, among neonates increased resistance of bacterial pathogens to antibiotics jeopardises improvements to child survival and causes an estimated 214,000 annual deaths globally (51).

Balancing the need to reduce overall antibiotic use with expanding essential access is

10 challenging. Improving global access to antibiotics will increase the selective pressure for AMR. Conversely, reducing antibiotic use is necessary to stem resistance, but perversely this may reduce the incentives for developing new antibiotics, which then would impede access (55). This potential unintended consequence from antibiotic conservation emphasizes the importance of finding new ways for drug developers to profit from innovation, rather than the current model based on drug prices and volumes.

\section{Learning from the economics of climate change}

The scale and multi-faceted nature of the challenges presented by AMR may seem overwhelming. Yet AMR is not the first such challenge the international community has

20 attempted to tackle. It is surely wise to reflect on what might be learned from other global challenges. There are some striking similarities between climate change and AMR $(56,57)$. Indeed, there may also be a direct link between the two phenomena, with recent evidence that higher temperatures are associated with higher resistance levels in common pathogens (58). Both challenges have been described as a global 'tragedy of the commons' in which individuals, acting rationally and according to their self-interest, collectively damage public 
goods (59-63). AMR and climate change are each driven by consumption of goods (carbon and antibiotics) that can provide people with valuable short-term benefits but impose longterm costs, such as existential threat from extreme weather or from life-threatening infections. Individuals may feel little incentive to change their course of action and forego short-term 5 benefits because the costs are highly uncertain and harmful events may happen far in the future, which people typically discount (64). However, the costs are unlikely to be avoided unless most people decide to reduce their carbon and antibiotic consumption.

The worst effects of both problems are likely to be distributed unequally across the world. In the most severe climate change scenarios, some of the small island developing 10 states such as the Maldives and Tuvalu could become uninhabitable (65). Likewise, increases in healthcare expenditures resulting from AMR are expected to be most severe in LMICs (66). Inadequate infection control systems within hospitals in LMICs can lead to the spread of healthcare-associated infections, and outbreaks caused by resistant pathogens, accompanied by significant increases in treatment costs, morbidity and mortality (67). Within

15 individual countries, the poor and vulnerable are also likely to be worst affected by climate shocks, for example, because of reliance on agricultural productivity for subsistence or employment (68). Similarly, because of its deleterious effect on labor and agricultural productivity, as well as healthcare cost, AMR is likely to make it harder to reduce extreme poverty and may increase the numbers who live in extreme poverty (66). Because of the time scale of cause and effect in climate change (69) and AMR (43) both raise questions of intergenerational equity, as future generations will not gain the benefits of carbon and antibiotic consumption but will face the brunt of the costs. Predicting the trajectory and extent of antibiotic resistance and temperature change is extremely difficult. On the one hand, increased temperatures resulting from carbon emissions are largely irreversible for 1,000 years after emissions stop (70), but on the other hand and with the right 
approach, antibiotic resistance may be reversible in months to years. As LMIC economies grow, both carbon emissions and antibiotic consumption will rise (Fig. 2) (71) and are likely to increase both temperatures and AMR. The trajectory of both problems is strongly dependent on population levels and, in the case of AMR, population densities (72). change. Firstly, in many countries doctors play a gatekeeping role with antibiotics, acting as 'agents' for society. Though imperfect, this principal-agent relationship can be harnessed to steer antibiotic consumption towards optimum levels by providing doctors with appropriate incentives. Unfortunately, there is no comparable agent to act as a gatekeeper for carbon

10 consumption. Secondly, reducing antibiotic use could potentially lower AMR in a much shorter timeframe than reducing carbon consumption would lower temperatures. Since results from policy interventions may be faster for AMR than for climate change, it might be easier for policymakers to agree to implement them. Conceivably, successful co-operation over AMR could develop goodwill, or even infrastructures, for forging co-operation on climate policy.

Considering the many parallels between AMR and climate change, it is instructive to consider the main economic approaches used to inform climate policy and where there is both consensus and controversy.

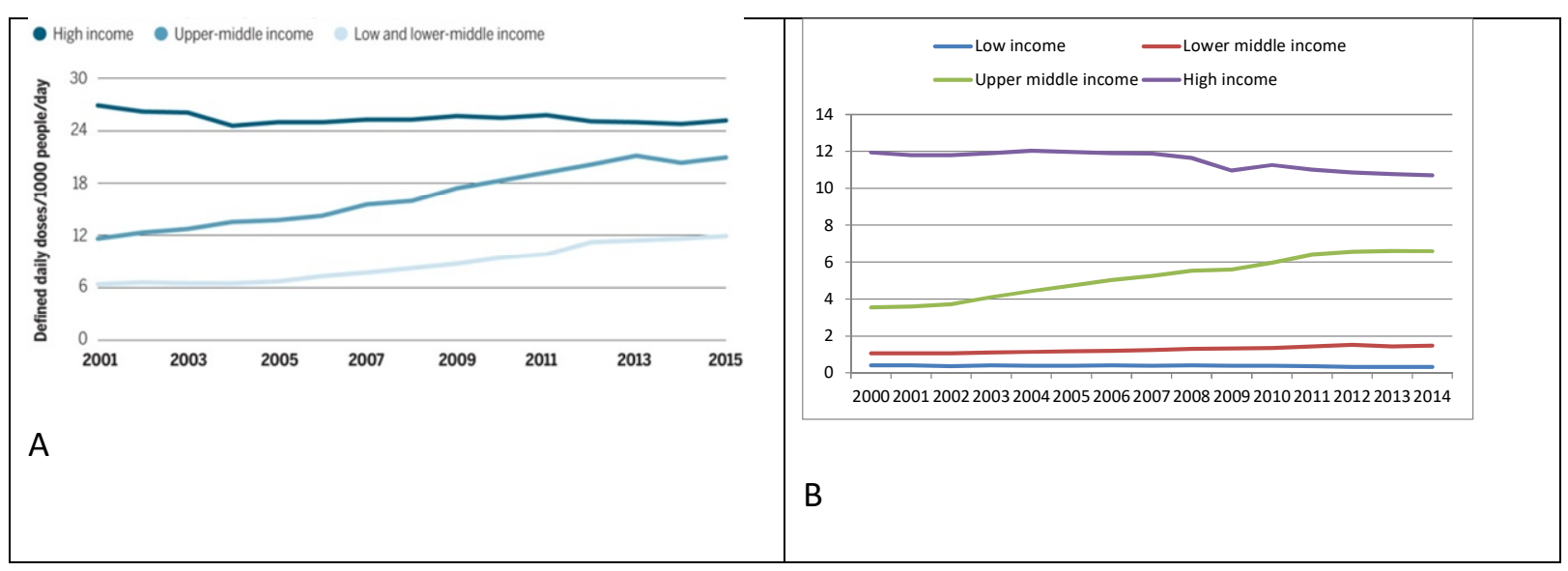




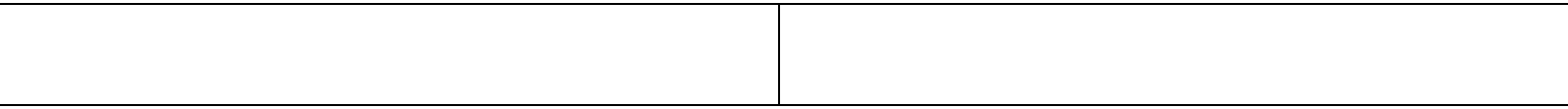

Fig. 2 Antibiotic consumption and CO2 emissions by country income (A) The overall trend in antibiotic consumption, in defined daily doses (DDD) per 1000 people per day, is flat in high income countries, but is increasing in middle income countries. [Credits: Graphic adapted from J. Brainard/Science; based on data by $5 \quad(71)$.

(B) The overall trend in $\mathrm{CO} 2$ emissions in metric tons per capita is flat in low and high income countries, but is increasing in middle income countries, especially upper middle. Source: Based on data from World Bank Databank

\section{Economic approaches to climate policy}

Economists agree that the full cost to society of burning carbon is greater than its current market cost (typically measured in US dollars per ton of $\left.\mathrm{CO}_{2}\right)(73-75)$. The gap between the full cost and market cost is known as the social cost of carbon (SCC). In theory, if the market price could be increased by an amount equal to the SCC, the laws of supply and demand would result in the quantity of carbon burned falling to the socially optimum level, mitigating climate change. This forms the theoretical economic basis for introducing a carbon tax, equal in size to the SCC. Economists broadly agree that global imposition of such a tax would be a sensible approach to tackle climate change. The leading alternative, of reducing emissions by issuing tradable emissions quotas, is similar in principle even if mechanics differ. Instead of intervening in the market price of carbon to achieve the socially optimum quantity, "cap and trade' would instead enforce the socially optimum quantity directly. However, in theory, the price should then rise to the same level that a tax equal to the SCC would achieve. To date, such global approaches have eluded the international community for a variety of reasons discussed below. More local initiatives have shown mixed success: during 2003-2015, 
gasoline taxes rose in 83 countries, although they were reduced in another 46, while several other countries continue to subsidize gasoline prices (76).

There are major difficulties and controversies over the implementation of tax and quota schemes. In large part the controversies arise over calculating the SCC. Estimates from

5 leading experts differ by an order of magnitude (11), leading to profoundly different implications for public policy, ranging from quite modest (77) to a requirement for immediate and significant cuts in emissions (69).

The standard approach to estimating the SCC has been to attempt a highly complex form of cost-benefit analysis using 'integrated assessment models' (IAMs). An IAM attempts 10 to monetize all the costs and benefits associated with carbon emissions to estimate the SCC. These costs and benefits are then discounted over some long-time horizon to give the net present value (NPV) of burning a marginal ton of carbon. The marginal SCC is equal to this value minus its market price.

There are three major uncertainties in the inputs to an IAM. The first is climate 15 sensitivity: the extent to which global temperatures would eventually rise if the atmospheric concentration of $\mathrm{CO} 2$ were to double. In AMR research an equivalent uncertainty is the proportion of a bacterial population that will ultimately become resistant. The second uncertainty is the economic impact resulting from whatever climate change might occur, sometimes called the 'damage function'. Both these sources of uncertainty have been 20 described as not only unknown, but "unknowable" $(11,78,79)$. In AMR, the damage function reflects the health costs of future resistant infections, as well as the consequent economic costs. The third uncertainty is the choice of discount rate with which to perform NPV calculations, which requires a judgement of intergenerational equity. This applies to cost-benefit analyses of both climate change and AMR. It is important to remember that over 25 long-time frames, small differences in discount rates can make large differences to the NPV 
of distant outcomes. These uncertainties have led many economists, such as Stern (80), to caution against an overly narrow focus on cost-benefit approaches to climate change mitigation, and to call for more dramatic and imminent emission reductions as insurance against the non-negligible possibility of catastrophic outcomes $(81,82)$. Theoretically, economists may largely agree that a global harmonized carbon tax, equal to the SCC, is an efficient response to climate change. However, lack of consensus regarding the size of the SCC is a major practical impediment. Instead, for reducing emissions climate policy has focused mainly on negotiating a limit for temperature increase on a country by country basis (11). The uncertainties are such that the choice of temperature target is highly contentious, both on environmental and economic grounds, but does offer a starting point for international negotiations on country-level emissions reductions.

What can we learn from the economics of climate change?

As the full cost to society of burning a ton of carbon is much greater than its market cost,

15 similarly the social cost of antibiotics (SCA) could be estimated via detailed analyses akin to IAMs. The costs and benefits of antibiotic use can be monetized and discounted over time to obtain the NPV of consuming some unit of antibiotics. In essence, the many difficulties identified by Coast et al. $(13,14)$ result from a lack of knowledge of the SCA. Like the SCC estimating the SCA presents analogous difficulties: how do increases or decreases in

20 antibiotic use translate into changes in resistance levels? What is the impact of increased resistance levels on health and GDP (i.e., 'damage function'). Not forgetting the thorny issue of the choice of discount rate and its implications for intergenerational equity. An important additional difficulty is that not all antibiotics, nor all resistances, are the same. Consequently, there is no fully satisfactory common unit of antibiotic quantity or, by extension, price in the way that there is for a ton of carbon (83). It may be more fruitful to model the trajectories, 
and costs and benefits, of resistances to specific antibiotics for specific infections. In addition, it might be valuable to gain a better understanding of the resistance trajectories of commensal bacteria, which are frequently exposed to antibiotics and may facilitate the spread of AMR (18).

Supposing that the social cost of using specific antibiotics for specific infections can be estimated, who carries the tax burden? If something analogous to the 'polluter pays' principle is applied to antibiotic use, in the sense that those who cause externalities must pick up the bill $(13,84)$, is this the consumer, the prescriber, the national healthcare system, or the government? It has been argued that taxing patients for antibiotic consumption is unlikely to

10 be effective, at least in high income settings, due to lack of price sensitivity (7). However, antibiotics could also be taxed at a more aggregated level - general practice, local or national authority. A tax on each antibiotic prescribed might provide an effective incentive for reducing prescriptions, and the revenue raised could be invested in antibiotic development.

Rather than taxing the price, and allowing the market to dictate the quantity of 15 antibiotics, as we have discussed an alternative may be to establish a regulatory body that gives prescribers permits (quotas) for prescribing, then lets the market determine the price (49). The quantity of permits available would be updated over time, according to resistance levels, and ideally the system would allow the permits to be traded (49). No such schemes have been implemented in practice, although since April 2015, the UK's Quality Premium 20 scheme has provided financial incentives to local Clinical Commissioning Groups (CCGs) (up to $£ 140,000$ for average sized CCGs which serve populations of around 280,000). Promisingly, this scheme has been accredited with having reduced antibiotic prescribing in primary care by about $7 \%$ in $2015 / 16(85)$.

Similar approaches could be tailored to other healthcare systems. The US Food and Drug Administration recently proposed a purchasable permit scheme for antimicrobials of 
last resort, where acute care institutions would pay a fixed licensing fee for the right to use a certain number of annual doses of the drug (86). The number of licensed doses could be tied to numbers of beds or likelihood of encountering certain microbes. An attractive feature of this proposal is that it would create a predictable revenue stream, through more foreseeable

5 licensing fees, for important antibiotics, in a way that could potentially decouple the return on investment from the volume used. Assigning antibiotics an 'option' rather than 'use' value could incentivize industry to develop important new antibiotics for which there would otherwise be too small a market to provide a sufficient return on investment. Another recent proposal for decoupling profits involves developers being paid an insurance premium to

10 provide access to antibiotics, which could be renegotiated at regular intervals (32).

Taxes and quotas have also been considered as potential tools for discouraging unnecessary use of antibiotics in animals. Eighty percent of all antibiotics used in the USA (87) are used in agriculture and aquaculture for routine non-therapeutic use as growth promoters, or as low-cost substitutes for hygiene measures to prevent infections (5). There is evidence that restricting antibiotic use in livestock is associated with a reduction in antibioticresistant bacteria in animals (88). The World Health Organization recently recommended a complete restriction on all antibiotic use for growth promotion and disease prevention in healthy livestock (89), and some European countries, including Denmark and Sweden, have imposed regulatory restrictions that have achieved substantial reductions in agricultural 20 antibiotic use while maintaining productive livestock sectors (90).

The global average quantity of antibiotic administered per kilogram of animal $(50 \mathrm{mg} / \mathrm{kg})$ has been proposed as a possible regulatory target (7). This could reduce total consumption by $64 \%$ (5). Alternatively, a user fee of $50 \%$ of the current price on veterinary antimicrobials could reduce global consumption by $31 \%$ (5). User fees have several advantages $(5,87)$ in that they can be easily administered either at the manufacturing or 
importing stage, they would deter low-value antibiotic practices and they would generate substantial annual revenues. User fees could be reinvested in R\&D for new antibiotics or antibiotic stewardship programs and be used to compensate LMICs, which may be disproportionately affected by a user fee, by investing in strategies that reduce the spread of

5 infection and improve veterinary services (5). In contrast, quantity restrictions would be difficult to enforce without adequate surveillance systems, which could be prohibitively expensive in LMICs (5). Whether through taxes or quotas, reducing predominantly nontherapeutic antibiotic use in agriculture is relatively uncomplicated compared with reducing human consumption.

Despite the shortcomings associated with the approach, combining biophysical and economic systems in climate IAMs is widely considered a worthy endeavour e.g. (80), even if the approach remains far from delivering convincing estimates of the SCC. Developing analogous models for antibiotics will be similarly valuable but will have similar shortcomings. As for climate change, the magnitude of the uncertainties and potential risks has led to calls to try to reduce antibiotic use as a type of insurance policy (2). An analogy with fire prevention has recently been used to illustrate the insurance value of antibiotics $(91$, 92), in that the microbiology laboratory acts as the smoke detector and medical staff as the firefighters. Like climate change, rather than waiting for analyses of optimum policies to curb AMR, precaution necessitates setting ambitious but pragmatic targets for reducing antibiotic use on a country by country basis without delay.

\section{Conclusions}

Economics, as a discipline, has made valuable contributions to the debate on climate change mitigation. Economic analyses have successfully informed recommendations by the

25 Intergovernmental Panel on Climate Change and decisions made by the international 
community, such as in the Paris Climate agreement. We would like to see economists rise to the challenge of similar initiatives for AMR (Table S1).

AMR presents particular challenges for LMICs, many of which already experience a high prevalence of AMR and its serious consequences. In LMICs there is woefully

5 inadequate access to desperately needed antibiotics among the poor, yet often substantial overconsumption of antibiotics among the middle classes. A lack of separation of prescribing and dispensing leads to supplier-induced demand, where patients consume more antibiotics than they would if they were better informed (32). Highlighting the tension between access and excess is the recent demonstration of substantial reductions in mortality from the mass

10 administration of 6-monthly single doses of the antibiotic azithromycin in children (93). Thus, future research should consider mechanisms that reduce overall antibiotic consumption without restricting essential access (94). If the cost of antibiotics is to increase, via taxation or quotas, it will be vital to develop mechanisms that reduce the risk that they will only be taken by those who can afford them.

The challenge of dealing with AMR is sandwiched between two classic market failures. On the demand side is the tragedy of the commons represented by the misuse of antibiotics as a public good and on the supply side is the lack of incentive for firms to develop new antibiotics. A key challenge on the supply side is the need to hold back the distribution of new antibiotics until AMR renders existing ones ineffective. The question here 20 is how to design incentives for production of a good that we must avoid using for as long as possible? It is now widely recognized that new product development requires the profits from innovation to be decoupled from prices and volumes (32-34). One insight from game theory is that none of the players, either individually or collectively, should be able to gain by leaving a coalition. Developing such an international agreement to limit antibiotic use is challenging, as countries vary widely in their incomes, capacities and objectives, and so too 
in the costs and benefits from membership (95). Enshrined in the Paris Agreement on climate change is a principle of 'Common but Differentiated Responsibility and Respective Capabilities.' Similar consideration should be given to the different challenges AMR presents in different countries.

\section{Prospects}

Like climate change, the potential costs of AMR are incredibly uncertain and potentially catastrophic. There is some consensus in the economics of climate change that we should treat cutting carbon emissions as an insurance policy. We suggest that a similar

10 paradigm shift is needed for tackling AMR.

There is an urgent need to improve the supply of new antibiotics. At the 2019 World Economic Forum meeting in Davos there were encouraging signs of recognition among policymakers of the need to work with industry to change the way antibiotic innovation is rewarded (96). Policymakers and philanthropists have recognized the importance of AMR,

15 and are increasingly making substantial research funds available, including to social science. A recent analysis of funding organization databases, across 19 countries and at EU level, found that during 2007-2013, a total of 1,243 antibacterial resistance research projects were funded, at a total public investment of $€ 1.3$ billion (97). There is a great opportunity for economists, across many different fields, to engage with this important and pressing global 20 problem. 


\section{References and Notes:}

1. S. Davies, Chief Medical Officer Annual Report 2011: Antimicrobial Resistance, Department of Health and Social Care, United Kingdom (2011). (2013).

3. A. Teillant, S. Gandra, D. Barter, D. J. Morgan, R. Laxminarayan, Potential burden of antibiotic resistance on surgery and cancer chemotherapy antibiotic prophylaxis in the USA: a literature review and modelling study. The Lancet Infectious Diseases 15(12), 1429-1437 (2015).

4. K.B. Pouwels, F.C.K. Dolk, D.R. Smith, J.V. Robotham, T. Smieszek, Actual versus 'ideal' antibiotic prescribing for common conditions in English primary care. Journal of Antimicrobial Chemotherapy 73(suppl_2), 19-26(2018).

5. T.P. Van Boeckel, E.E. Glennon, , D. Chen, M. Gilbert, , T.P. Robinson, B.T. Grenfell, S.A. Levin, S. Bonhoeffer, R. Laxminarayan, Reducing antimicrobial use in food animals. Science 357(6358), 1350-1352 (2017). 
7. Review on Antimicrobial Resistance, Tackling Drug-Resistant Infections Globally: Final

Report and Recommendations. Available at http://amr-review.org/Publications.html (2016).

8. World Bank, Drug-Resistant Infections: A Threat to Our Economic Future. Washington, DC:

World Bank. License: Creative Commons Attribution CC BY 3.0 IGO (2017).

9. M.E. de Kraker, A.J. Stewardson, S. Harbarth, Will 10 million people die a year due to antimicrobial resistance by 2050? PLoS medicine 13(11), p.e1002184 (2016). A.B. Feigl, T. Gaziano, M. Mowafi, A. Pandya, K. Prettner, L. Rosenberg, B. Seligman, A. Stein, C. Weinstein, The Global Economic Burden of Non-communicable Diseases. Geneva: World Economic Forum (2011). 84(335), 345-364 (2017).

12. R. Laxminarayan, D. Sridhar, M. Blaser, M. Wang, M. Woolhouse, Achieving global targets for antimicrobial resistance. Science 353(6302), 874-875 (2016).

13. J. Coast, R.D. Smith, M.R. Millar, Superbugs: should antimicrobial resistance be included as a cost in economic evaluation? Health Economics 5(3), 217-226 (1996). 
14. J. Coast, R.D. Smith, A.M. Karcher, P. Wilton, M. Millar, Superbugs II: how should economic evaluation be conducted for interventions which aim to contain antimicrobial resistance? Health Economics 11(7), 637-647 (2002).

15. T. Day, A.F, Does high-dose antimicrobial chemotherapy prevent the evolution of resistance? PLoS Computational Biology, 12(1):e1004689 (2016).

16. N.R. Naylor, R. Atun, N. Zhu, K. Kulasabanathan, S. Silva, A. Chatterjee, G.M. Knight, J.V. Robotham, Estimating the burden of antimicrobial resistance: a systematic literature review. Antimicrobial Resistance \& Infection Control 7(1), p.58 (2018).

17. D.M. Livermore, The 2018 Garrod Lecture: Preparing for the Black Swans of resistance. Journal of Antimicrobial Chemotherapy 10.1093/jac/dky265 (2018). T. Smieszek, Association between use of different antibiotics and trimethoprim resistance: going beyond the obvious crude association. Journal of Antimicrobial Chemotherapy 73(6), 1700-1707 (2018). antibiotic resistance. Science, 351(6268), p.aad3292.

20. D. Carter, A. Charlett, S. Conti, J.V. Robotham, A.P. Johnson, D.M. Livermore, T. Fowler, 
resistance in the UK: Bayesian analysis of an expert elicitation study. Antibiotics 6(1), p.9 (2017).

21. D.I. Andersson, D. Hughes, D, Antibiotic resistance and its cost: is it possible to reverse resistance? Nature Reviews Microbiology 8(4), p.260 (2010).

22. V.I. Enne, P.M. Bennett, D.M. Livermore, L.M. Hall, Enhancement of host fitness by the sul2-coding plasmid p9123 in the absence of selective pressure. Journal of Antimicrobial Chemotherapy 53(6), 958-963 (2004).

23. D. Hughes, D.I. Andersson, Evolutionary consequences of drug resistance: shared principles across diverse targets and organisms. Nature Reviews Genetics, 16(8), p.459 (2015).

24. MacLean, R.C. and Vogwill, T., 2014. Limits to compensatory adaptation and the persistence of antibiotic resistance in pathogenic bacteria. Evolution, medicine, and public health, 2015(1), pp.4-12.

25. M. Sundqvist, P. Geli, D.I. Andersson, M. Sjölund-Karlsson, A. Runehagen, H. Cars, K. Abelson-Storby, O. Cars,G. Kahlmeter, Little evidence for reversibility of trimethoprim resistance after a drastic reduction in trimethoprim use. Journal of Antimicrobial Chemotherapy 65(2), 350-360 (2009).

26. V.I. Enne, D.M. Livermore, P. Stephens, L.M. Hall, Persistence of sulphonamide resistance in Escherichia coli in the UK despite national prescribing restriction. The Lancet 357(9265), $1325-1328$ (2001). 
27. C.C. Butler, F. Dunstan, M. Heginbothom, B. Mason, Z. Roberts, S. Hillier, R. Howe, S. Palmer, A. Howard, Containing antibiotic resistance: decreased antibiotic-resistant coliform urinary tract infections with reduction in antibiotic prescribing by general practices. $\mathrm{Br} J \mathrm{Gen}$ Pract 57(543), 785-792 (2007).

28. C. Nathan, O. Cars, Antibiotic resistance - problems, progress, and prospects. New England Journal of Medicine, 371(19), 1761-1763 (2014).

29. M. Renwick, E. Mossialos, What are the economic barriers of antibiotic R\&D and how can we overcome them? Expert Opinion on Drug Discovery 10.1080/17460441.2018.1515908 (2018).

30. P. Sharma, A. Towse, New Drugs to Tackle Antimicrobial Resistance: Analysis of EU Policy Options (2010). Available at SSRN http://dx.doi.org/10.2139/ssrn.2640028 (2010).

31. K.H. Luepke, K.J. Suda, H. Boucher, R.L. Russo, M.W. Bonney, T.D. Hunt, J.F. Mohr III, Past, present, and future of antibacterial economics: increasing bacterial resistance, limited antibiotic pipeline, and societal implications. Pharmacotherapy: The Journal of Human Pharmacology and Drug Therapy, 37(1),71-84 (2017). 
32. C.M. Morel, S.E. Edwards, S. Harbarth, Preserving the 'commons': addressing the sustainable use of antibiotics through an economic lens. Clinical Microbiology and Infection 23, 718-722 (2017).

33. K. Outterson, J.H. Powers, G.W. Daniel, M.B. McClellan, Repairing the broken market for antibiotic innovation. Health Affairs 34(2), 277-285 (2015).

34. K. Outterson, U. Gopinathan, C. Clift, A.D. So, C.M. Morel, J.A. Røttingen, Delinking Investment in Antibiotic Research and Development from sales revenues: the challenges of transforming a Promising Idea into reality. PLoS Medicine 13(6), p.e1002043 (2016).

35. P. Collignon, J.J. Beggs, T.R. Walsh, S. Gandra, R. Laxminarayan, Anthropological and socioeconomic factors contributing to global antimicrobial resistance: a univariate and multivariable analysis. The Lancet Planetary Health 2(9), pp.e398-e405 (2018).

36. H. Lishman, C. Costelloe, S. Hopkins, A.P. Johnson, R. Hope, R. Guy, B. Muller-Pebody, A. Holmes, P. Aylin, Exploring the relationship between primary care antibiotic prescribing for urinary tract infections, Escherichia coli bacteraemia incidence and antibiotic resistance: an ecological study. International Journal of Antimicrobial Agents 10.1016/j.ijantimicag.2018.08.013 (2018). 
37. R.D. Smith, M. Yago, M. Millar, J. Coast, Assessing the macroeconomic impact of a healthcare problem: the application of computable general equilibrium analysis to antimicrobial resistance. Journal of Health Economics 24, 1055-1075 (2005).

38. P. Shrestha, B.S. Cooper, J. Coast, R. Oppong, N.D.T. Thuy, T. Phodha, O. Celhay, P.J. Guerin, H. Wertheim, Y. Lubell, Enumerating the economic cost of antimicrobial resistance per antibiotic consumed to inform the evaluation of interventions affecting their use. Antimicrobial Resistance \& Infection Control 7(1), p.98 (2018). infections in primary care are symptomatic for longer and increase workload: outcomes for patients with E. coli UTIs. Br J Gen Pract 56(530), pp.686-692 (2006).

40. M.F. Alam, D. Cohen, C. Butler, F. Dunstan, Z. Roberts, S. Hillier, S. Palmer, The additional costs of antibiotics and re-consultations for antibiotic-resistant Escherichia coli urinary tract infections managed in general practice. International journal of antimicrobial agents 33(3), 255257 (2009).

41. G. Mooney, M. Ryan, Agency in health care: getting beyond first principles. Journal of Health Economics 12(2), 125-135 (1993).

42. M. Angell, The doctor as double agent. Kennedy Institute of Ethics Journal 3(3), 279-286 (1993). 
43. J. Coast, R.D. Smith, Distributional Considerations in Economic Responses to Antimicrobial Resistance. Public Health Ethics 8(3), 225-237 (2015).

44. J. Currie, W. Lin, J. Meng, Addressing Antibiotic Abuse in China: An Experimental Audit Study. Journal of Development Economics 110, 39-51 (2014).

45. M. Filippini, F. Heimsch, G. Masiero, Antibiotic consumption and the role of dispensing physicians. Regional Science and Urban Economics 49, 242-251 (2014).

46. S. Coenen, N. Francis, M. Kelly, K. Hood, J. Nuttall, P. Little, T.J. Verheij, H. Melbye, H. Goossens, C.C. Butler, GRACE Project Group, Are patient views about antibiotics related to clinician perceptions, management and outcome? A multi-country study in outpatients with acute cough. PloS One 8(10), p.e76691 (2013).

47. B. Huttner, H. Goossens, T. Verheij, S. Harbarth, Characteristics and outcomes of public campaigns aimed at improving the use of antibiotics in outpatients in high-income countries. The Lancet Infectious Diseases 10(1), 17-31 (2010).

48. L.S.J. Roope, S. Tonkin-Crine, C.C. Butler, D. Crook, T. Peto, M. Peters, A.S. Walker, S. Wordsworth, Reducing demand for antibiotic prescriptions: evidence from an online survey of the general public on the interaction between preferences, beliefs and information, United Kingdom, 2015. Eurosurveillance 23(25),1700424 (2018). 
49. R.D. Smith, J. Coast, Controlling antimicrobial resistance: a proposed transferable permit market. Health Policy 43, 219-232 (1998).

50. B. Spellberg, J. Bartlett, R. Wunderink, D.N. Gilbert, Novel approaches are needed to develop tomorrow's antibacterial therapies. American journal of respiratory and critical care medicine 191(2), 135-140 (2015).

51. R. Laxminarayan, P. Matsoso, S. Pant, C. Brower, J.A. Røttingen, K. Klugman, S. Davies, Access to effective antimicrobials: a worldwide challenge. The Lancet 387(10014), 168-175 (2016).

52. Y. Hsia, M. Sharland, C. Jackson, I.C. Wong, N. Magrini, J.A. Bielicki, Consumption of oral antibiotic formulations for young children according to the WHO Access, Watch, Reserve (AWaRe) antibiotic groups: an analysis of sales data from 70 middle-income and high-income countries. The Lancet Infectious Diseases 10.1016/S1473-3099(18)30547-4 (2018).

53. P. Das, R. Horton, Antibiotics: achieving the balance between access and excess. The Lancet 387(10014):102-104 (2016).

54. L. Liu, S. Oza, D. Hogan, J. Perin, I. Rudan, J.E. Lawn, S. Cousens, C. Mathers, R.E. Black, Global, regional, and national causes of child mortality in 2000-13, with projections to inform post-2015 priorities: an updated systematic analysis. The Lancet 385(9966), 430-440 (2015). 
55. C. Årdal, K. Outterson, S.J. Hoffman, A. Ghafur, M. Sharland, N. Ranganathan, R. Smith, A. Zorzet, J. Cohn, D. Pittet, N. Daulaire. International cooperation to improve access to and sustain effectiveness of antimicrobials. The Lancet 387(10015), 296-307 (2016).

56. W. Pearce, M. Mahony, S. Raman, Science advice for global challenges: Learning from trade-offs in the IPCC. Environmental Science \& Policy 80, 125-131 (2018).

57. M. Woolhouse, J. Farrar, Policy: An intergovernmental panel on antimicrobial resistance. Nature 509, 555-557 (2014).

58. D.R. MacFadden, S.F. McGough, D. Fisman, M. Santillana, J.S. Brownstein, Antibiotic resistance increases with local temperature. Nature Climate Change, p.1 (2018).

60. M. Cully, The politics of antibiotics. Nature 509(7498), p.S16 (2014). social dilemma and the prevention of simulated dangerous climate change. Proceedings of the National Academy of Sciences 105(7), 2291-2294 (2008). 
62. R.D. Smith, J. Coast, Antimicrobial resistance: a global response. Bulletin of the World Health Organisation 80, 126-133 (2002).

63. R.D. Smith, J. Coast, Antimicrobial drug resistance. In: Smith RD, Beaglehole R, Woodward D, Drager N (eds). Global Public Goods for Health: a health economic and public health perspective, Oxford University Press, chapter 4 (2003).

64. S. Frederick, G. Loewenstein, T. O’Donoghue, Time discounting and time preference: A critical review. Journal of Economic Literature 40(2), 351-401 (2002).

65. C. Betzold, Adapting to climate change in small island developing states. Climatic Change 133(3), 481-489 (2015).

66. S.A. Ahmed, E. Barış, D.S. Go, H. Lofgren, I. Osorio-Rodarte, K. Thierfelder, Assessing the global poverty effects of antimicrobial resistance. World Development 111, 148-160 (2018).

67. R. Laxminarayan, A. Duse, C. Wattal, A.K. Zaidi, H.F. Wertheim, N. Sumpradit, E. Vlieghe, G.L. Hara, I.M. Gould, H. Goossens, C. Greko, Antibiotic resistance-the need for global solutions. The Lancet Infectious Diseases 13(12), 1057-1098 (2013).

68. C.A. Harvey, Z.L. Rakotobe, N.S. Rao, R. Dave, H. Razafimahatratra, R.H. Rabarijohn, H. Rajaofara, J.L. MacKinnon, Extreme vulnerability of smallholder farmers to agricultural risks and climate change in Madagascar. Phil. Trans. R. Soc. B 369(1639), p.20130089 (2014). 
69. N.H. Stern, The Economics of Climate Change: The Stern Review. Cambridge University Press (2007).

70. S. Solomon, G.K. Plattner, R. Knutti, P. Friedlingstein, Irreversible climate change due to carbon dioxide emissions. Proceedings of the National Academy of Sciences 106(6), 1704-1709 (2009).

71. E.Y. Klein, T.P. Van Boeckel, E.M. Martinez, S. Pant, S. Gandra, S.A. Levin, H. Goossens, R. Laxminarayan, Global increase and geographic convergence in antibiotic consumption between 2000 and 2015. Proceedings of the National Academy of Sciences, p.201717295 (2018).

72. N. Bruinsma, J.M. Hutchinson, A.E. Van Den Bogaard, H. Giamarellou, J. Degener, E.E. Stobberingh, Influence of population density on antibiotic resistance. Journal of Antimicrobial Chemotherapy 51(2), 385-390 (2003).

73. W.D. Nordhaus, Revisiting the social cost of carbon. Proceedings of the National Academy of Sciences, p.201609244 (2017). Murray, R. Newell, R. Richels, A. Rowell, Using and improving the social cost of carbon. Science, 346(6214), pp.1189-1190 (2014). 
75. M.L. Weitzman, Tail-hedge discounting and the social cost of carbon. Journal of Economic Literature, 51(3), pp.873-82 (2013).

76. M.L. Ross, C. Hazlett, P. Mahdavi, Global progress and backsliding on gasoline taxes and subsidies. Nature Energy 2(1), p.16201 (2017).

77. W.D. Nordhaus, Estimates of the social cost of carbon: background and results from the RICE-2011 model (No. w17540). National Bureau of Economic Research 10.3386/w17540 (2011).

10

78. M.R. Allen, D.J. Frame, Call Off the Quest. Science 318,582-583 (2007).

79. R.S. Pindyck, Climate change policy: what do the models tell us? Journal of Economic Literature 51(3), 860-72 (2013).

15

80. N. Stern, Current climate models are grossly misleading. Nature 530, 407 (2016).

81. M.L. Weitzman, On modeling and interpreting the economics of catastrophic climate change. The Review of Economics and Statistics 91(1), 1-19 (2009).

82. M.L. Weitzman, Fat-tailed uncertainty in the economics of catastrophic climate change. Review of Environmental Economics and Policy 5(2), 275-292 (2011). 
83. R. Laxminarayan, K.P. Klugman, Communicating trends in resistance using a drug resistance index. BMJ open 1(2), p.e000135 (2011).

84. J. Coast, R.D. Smith, M.R. Millar, An economic perspective on policy to reduce antimicrobial resistance. Social Science \& Medicine 46, 29-38 (1998).

85. Public Health England. English surveillance programme for antimicrobial utilisation and resistance (ESPAUR) Report 2017. PHE (2017).

https://assets.publishing.service.gov.uk/government/uploads/system/uploads/attachment_data/file /656611/ESPAUR_report_2017.pdf [Accessed 22 September 2018].

86. Food and Drug Administration, statement released on $18^{\text {th }}$ June 2018.

https://www.fda.gov/NewsEvents/Newsroom/PressAnnouncements/ucm610503.htm?utm_campa ign $=06122018$ Statement_FDA $\%$ E2\%80\%99s\%20efforts\%20to\%20foster\%20new\%20tools\%2 0to\%20fight\%20antimicrobial\%20resistance\&utm_medium=email\&utm_source=Eloqua [Accessed 18 ${ }^{\text {th }}$ August 2018]

87. A. Hollis, Z. Ahmed, Preserving antibiotics, rationally. New England Journal of Medicine 369(26), 2474-2476 (2013).

88. K.L. Tang, N.P. Caffrey, D.B. Nóbrega, S.C. Cork, P.E. Ronksley, H.W. Barkema, A.J. Polachek, H. Ganshorn, N. Sharma, J.D. Kellner, W.A. Ghali, Restricting the use of antibiotics in food-producing animals and its associations with antibiotic resistance in food-producing 
animals and human beings: a systematic review and meta-analysis. The Lancet Planetary

Health 1(8), pp.e316-e327 (2017).

89. WHO guidelines on use of medically important antimicrobials in food-producing animals. Geneva: World Health Organization Licence: CC BY-NC-SA 3.0 IGO (2017).

90. C. Cogliani, H. Goossens, C. Greko, Restricting antimicrobial use in food animals: lessons from Europe. Microbe 6(6), p.274 (2011).

91. DRIVE-AB Final Report. Revitalizing the Antibiotic Pipeline: Stimulating Innovation While Driving Sustainable Use and Global Access (2018). Available at http://drive-ab.eu/drive-aboutputs/drive-ab-reports/

92. J.H. Rex, K. Outterson, Antibiotic reimbursement in a model delinked from sales: a benchmark-based worldwide approach. The Lancet Infectious Diseases 16(4), 500-505 (2016).

93. J.D. Keenan, R.L. Bailey, S.K. West, A.M. Arzika, J. Hart, J. Weaver, K. Kalua, Z. Mrango, K.J. Ray, C. Cook, E. Lebas, Azithromycin to Reduce Childhood Mortality in Sub-Saharan Africa. New England Journal of Medicine 378(17), 1583-1592 (2018).

94. M. Mendelson, J.A. Røttingen, U. Gopinathan, D.H. Hamer, H. Wertheim, B. Basnyat, C. Butler, G. Tomson, M. Balasegaram, Maximising access to achieve appropriate human 
antimicrobial use in low-income and middle-income countries. The Lancet 387(10014), 188-198 (2016).

95. A. Hollis, P. Maybarduk, Antibiotic resistance is a tragedy of the commons that necessitates global cooperation. The Journal of Law, Medicine \& Ethics 43(3_suppl), 33-37 (2015).

96. Speech at World Economic Forum in Davos, 2019. Transcript available at https://www.gov.uk/government/speeches/antimicrobial-resistance-needs-an-urgent-globalresponse [Accessed 5th February, 2019].

97. R. Kelly, G. Zoubiane, D. Walsh, R. Ward, H. Goossens, Public funding for research on antibacterial resistance in the JPIAMR countries, the European Commission, and related European Union agencies: a systematic observational analysis. The Lancet Infectious Diseases 16(4), 431-440 (2016).

98. R. Laxminarayan, G.M. Brown, Economics of antibiotic resistance: a theory of optimal use. Journal of Environmental Economics and Management 42(2), 183-206 (2001).

99. S. Jain, P. Upadhyaya, J. Goyal, A. Kumar, P. Jain, V. Seth, V.V. Moghe, A systematic review of prescription pattern monitoring studies and their effectiveness in promoting rational use of medicines. Perspectives in Clinical Research 6(2), p. 86 (2015). 
100. M.J. Smith, J.S. Gerber, A.L. Hersh, Inpatient antimicrobial stewardship in pediatrics: a systematic review. Journal of the Pediatric Infectious Diseases Society 4(4), pp.e127-e135 (2015). analysis of clinical and economic outcomes from the implementation of hospital-based antimicrobial stewardship programs. Antimicrobial Agents and Chemotherapy 60(8), 4840-4852 (2016). Ten-Foe, M.J. Postma, B. Sinha, Cost-minimization model of a multidisciplinary antibiotic stewardship team based on a successful implementation on a urology ward of an academic hospital. PloS One 10(5), p.e0126106 (2015). prescriptions. Journal of Economic Behavior \& Organization 135, 39-52 (2017).

104. R. Gonzales, K.K. Corbett, B.A. Leeman- Castillo, J. Glazner, K. Erbacher, C.A. Darr, S. Wong, J.H. Maselli, A. Sauaia, K. Kafadar, The "minimizing antibiotic resistance in Colorado" project: impact of patient education in improving antibiotic use in private office practices. Health Services Research 40(1), 101-116 (2005). 
105. M. Filippini, L.G. Ortiz, G. Masiero, Assessing the impact of national antibiotic campaigns in Europe. The European Journal of Health Economics 14(4), 587-599 (2013).

106. C.C. Butler, S.A. Simpson, F. Dunstan, S. Rollnick, D. Cohen, D. Gillespie, M.R. Evans, programme to reduce antibiotic dispensing in primary care: practice based randomised controlled trial. BMJ 344, p.d8173 (2012).

Acknowledgments: Funding: This research was funded by the National Institute for Health Research Health Protection Research Unit (NIHR HPRU) in Healthcare Associated Infections and Antimicrobial Resistance at the University of Oxford [grant number HPRU-2012-10041] and in partnership with Public Health England (PHE). The support of the Economic and Social Research Council (UK) (grant number ES/P008232/1) is gratefully acknowledged. LSJR, LA, ASW and SW are supported by funding from the National Institute for Health Research (NIHR) Oxford Biomedical Research Centre (BRC). LA and CCB are supported by funding from the NIHR Community Healthcare MedTech and In-vitro Diagnostics Co-operative (MIC). The views expressed are those of the authors and not necessarily those of the NHS, the NIHR or the Department of Health and Social Care; Author contributions: LSJR led the drafting of the paper, with contributions from all authors. The corresponding author attests that all listed authors meet authorship criteria and that no others meeting the criteria have been omitted; Competing interests: Authors declare no competing interests; Data and materials availability: Figure 1 is based on data from reference (35), as mentioned in the Figure caption. As credited in the caption to Figure 2, this graphic by J. Brainard/Science; based on data by reference (71). 
DIAAS

\section{Supplementary Material}

\section{Table S1. Priorities for economic research in AMR}

\begin{tabular}{|c|c|c|c|}
\hline Research topic & Field of economics & Existing research & Open questions \\
\hline \multirow[t]{3}{*}{ Policies to reduce antibiotic use } & Game Theory, Industrial & Proposed cap and trade scheme (49) & \multirow{3}{*}{$\begin{array}{l}\text { Could an efficient international cap and trade scheme be designed for antibiotics, as proposed by Smith and Coast } \\
\text { (49)? How could the caps be determined appropriately, accounting for differences in resistance levels across } \\
\text { countries? How could such a scheme encourage use of a diverse range of antibiotics - and is this actually desirable? }\end{array}$} \\
\hline & Organisation, Health & Proposed strategies for a global response (62) & \\
\hline & Economics & Economic aspects of sustainable use of antibiotics (32) & \\
\hline \multirow[t]{2}{*}{ Optimal use of antibiotics } & Health Economics & Theory of optimal use (98) & \multirow{5}{*}{$\begin{array}{l}\text { Should new antibiotics only be used after it has been demonstrated that pathogens have become sufficiently resistant to } \\
\text { existing antibiotics? } \\
\text { What mechanisms can be designed in LMICs to meet the dual challenges of inappropriate antibiotic consumption and } \\
\text { lack of access to necessary antibiotics? }\end{array}$} \\
\hline & & Prescription pattern monitoring studies (99) & \\
\hline \multirow[t]{3}{*}{ Access in LMIC countries } & Development Economics, & Global trends in antibiotic consumption (71) & \\
\hline & Industrial Organisation, & Normative starting points for the analysis of distributional issues (43) & \\
\hline & Mechanism Design & Impact of AMR on global poverty (66) & \\
\hline \multirow[t]{3}{*}{ Antibiotics in agriculture } & Agricultural Economics, & Impact on AMR of interventions that reduce antibiotic use in animals (88) & \multirow[t]{3}{*}{ How is reducing the use of antibiotics in agriculture likely to affect food costs? } \\
\hline & Environmental Economics & Restriction of antibiotic use as growth promoters for a & \\
\hline & & Policies to reduce antibiotic use in food animals (5) & \\
\hline \multirow[t]{5}{*}{ Development of new antibiotics } & Game Theory, Industrial & Incentives to stimulate development of antibiotics $(30,91)$ & \multirow{5}{*}{$\begin{array}{l}\text { The O'Neill report (7) proposed that governments consider a small levy on drug-developers to raise funding for } \\
\text { market entry rewards, whereby firms that invest in R\&D that is useful for AMR can deduct this investment from the } \\
\text { charge owed by all players within the industry. How efficient is such a scheme likely to be? Are public-private } \\
\text { partnerships such as CARB-X } X \text { likely to perform better? What other mechanisms can economists find to incentivise a } \\
\text { leap forward in antibiotic innovation? }\end{array}$} \\
\hline & Organisation & Benchmark approach for antibiotic reimbursement (92) & \\
\hline & & Economic barriers to antibiotic R\&D (29) & \\
\hline & & Delinking investment from sales (34) & \\
\hline & & Policy reforms to encourage both innovation and sustainable use (33) & \\
\hline \multirow{6}{*}{$\begin{array}{l}\text { Current and future impact of AMR in } \\
\text { the health system }\end{array}$} & Health Economics & Impact of AMR on surgery and chemotherapy for cancer in the US (3) & \multirow{6}{*}{$\begin{array}{l}\text { Can the current and future impact of AMR throughout the health system be estimated? What, for example, are the } \\
\text { implications for cancer care? Are major changes already needed to hospitals to stem AMR - for example by building } \\
\text { more isolation wards, or making it standard that ventilation systems in such wards generate negative pressure, allowing } \\
\text { air to flow in but not escape? }\end{array}$} \\
\hline & & Limitations of current economic analyses of the costs of AMR (2) & \\
\hline & & Inpatient antimicrobial stewardship $(100,101,102)$ & \\
\hline & & Modelling the cost of AMR per antibiotic consumed (38) & \\
\hline & & Economic burden of AMR (16) & \\
\hline & & Uncertainty around current estimates of the burden of AMR (9) & \\
\hline \multirow[t]{3}{*}{ Macroeconomic effects of AMR } & Labour Economics, & Limitations of current economic analyses of the costs of AMR (2) & \multirow[t]{3}{*}{ More research is required on the macroeconomic effects of AMR, for example on labour force participation. } \\
\hline & Macroeconomics & Modelling the cost of AMR per antibiotic consumed (38) & \\
\hline & & Modelling the macroeconomic impact of AMR in a general equilibrium model (37) & \\
\hline \multirow{4}{*}{$\begin{array}{l}\text { Preferences and behavioural } \\
\text { interventions }\end{array}$} & Behavioural economics, & Nudging techniques can reduce antibiotic use (103) & \multirow{4}{*}{$\begin{array}{l}\text { Research on the (revealed and stated) preferences of patients, clinicians, firms and governments is needed to better } \\
\text { understand the likely responses to various incentives. }\end{array}$} \\
\hline & Experimental economics & Patient education can reduce antibiotic use in adults (104) & \\
\hline & & National antibiotic campaigns can reduce antibiotic consumption (105) & \\
\hline & & Education of general practitioners reduces antibiotic use (106) & \\
\hline
\end{tabular}

NOTES: 1. CARB-X is a non-profit public-private partnership which provides financial, scientific and commercial support to speed

up the development of products focused on drug-resistant bacteria. In schemes such as CARB-X, after a certain number months, an

evaluation is made of whether the product being developed is still promising. If not, funding is terminated; 2. 'LMIC' is low or middle income country; 3. 'AMR' is antimicrobial resistance; 'R\&D' is research and development. 